УДК 547.314

\title{
HОВЫЕ КОМПОНЕНТЫ СМОЛЫ КОРНЕЙ BILACUNARIA MICROCARPA (M. BIEB.) PIMENOV \& V.N. TIKHOM.
}

\author{
() Н.Х. Микаилова, С.В. Серкеров" \\ Институт ботаники Национальной академии наук Азербайджана, \\ Бадамдарское шоссе, 40, Баку, AZ1073, (Азербайджан), \\ e-mail: s.serkerov@mail.ru
}

Из суммы экстрактивных веществ, полученных экстракцией ацетоном мелко измельченных сухих корней Bilacunaria microcarpa (M. Bieb.) Pimenov \& V.N. Tikhom. методом колоночной хроматографии, кроме ранее выделенных кумаринов остола $\left(\mathrm{C}_{15} \mathrm{H}_{16} \mathrm{O}_{3}\right.$, т. пл. 84-85 $\left.{ }^{\circ} \mathrm{C}\right)$, бергаптена $\left(\mathrm{C}_{12} \mathrm{H}_{8} \mathrm{O}_{4}\right.$, т. пл. $\left.188-189{ }^{\circ} \mathrm{C}\right)$, изоимператорина $\left(\mathrm{C}_{16} \mathrm{H}_{14} \mathrm{O}_{6}\right.$, т. пл. 109 $\left.110{ }^{\circ} \mathrm{C}\right)$, оксипеуцеданина $\left(\mathrm{C}_{16} \mathrm{H}_{14} \mathrm{O}_{5}\right.$, т. пл. $\left.141-143{ }^{\circ} \mathrm{C}\right)$, оксипеуцеданин гидрата $\left(\mathrm{C}_{16} \mathrm{H}_{16} \mathrm{O}_{6}\right.$, т. пл. $\left.132-134{ }^{\circ} \mathrm{C}\right)$, выделены два кристаллических вещества состава $\mathrm{C}_{15} \mathrm{H}_{14} \mathrm{O}_{4}$, т. пл. $108-109^{\circ} \mathrm{C}$ (I), и $\mathrm{C}_{16} \mathrm{H}_{16} \mathrm{O}_{6}$, т. пл. $127-129^{\circ} \mathrm{C}$ (II).

На основании спектральных (ИК-, ЯMP ${ }^{1} \mathrm{H},{ }^{13} \mathrm{C},{ }^{13} \mathrm{C}$ Dept, Dept 90) данных доказано, что они имеют строение, идентичное строению пеуцеданина и прангенин гидрата соответственно.

Ключевые слова: Bilacunaria, кумарины, фурокумарины, гидрат прангенина; ИК-спектроскопия, ЯМР-спектроскопия.

\section{Введение}

Во флоре Азербайджана род Bilacunaria представлен двумя видами: Bilacunaria microcarpa (=Hippomaratrum microcarpum (М.B.) В. Fedtsch.) и B. capsicum (H. caspicum (DC) Grossh.) [2]. Согласно литературным данным, из исследуемого растительного материала выделены кумаринпроизводные умбеллиферон, остол, бергаптен, оксипеуцеданин, оксипеуцеданин гидрат, изоимператорин, ксантотоксин, прангенин и изопимпинеллин [3].

\section{Экспериментальная часть}

В качестве материала для исследований использовали корни B. microcarpa, собранные 9 августа 2012 г. в период цветения - начала плодоношения в окрестностях с. Джек Кубинского района Азербайджанской Республики. Гербарные материалы были определены Н.П. Мехтиевой и хранятся в коллекциях Института Ботаники НАН Азербайджана (№103852).

Сумму биологически активных веществ получили путем экстракции корней растения ацетоном. Выделение веществ в индивидуальном состоянии осуществляли методом хроматографии на колонке, заполненной нейтральной окисью алюминия (III-IV ст. акт.).

Индивидуальность полученных веществ определяли методом тонкослойной хроматографии на пластинках Silufol UV 254. Температуру плавления определяли на столике Боэтиуса. ИК-спектры снимали на спектрометре Varian 640 IR в вазелиновом масле.

Спектры ${ }^{1} \mathrm{H}$ и ${ }^{13} \mathrm{C}$ ЯМР снимали на спектрометре Bruker 300 с резонансной частотой 300 МГц для ${ }^{1} \mathrm{H}$ и 75 МГц для ядер ${ }^{13} \mathrm{C}$. Растворитель - DMSO-d 6 . Химические сдвиги даны по $\delta$-шкале. Внутренний стан-

Микаилова Нигяр Хизри кызы - диссертант

Серкеров Сираджеддин Вели оглу - заслуженный деятель науки Азербайджана, доктор химических наук, профессор, главный научный сотрудник, e-mail: s.serkerov@mail.ru

\section{дарт - ТМС.}

Получение суммы биологически активных веществ. 535,0 г мелко измельченных воздушносухих корней Bilacunaria microcarpa трехкратно экстрагировали ацетоном (каждый раз в течение 3

\footnotetext{
* Автор, с которым следует вести переписку.
} 
дней). Ацетон отфильтровывали и отгоняли на водяной бане при помощи роторного испарителя. Остаток 35,0 г - темно-коричневая смола. Выход 6,54\%.

Хроматографирование суммы биологически активных веществ. 15,0 г смолы хроматографировали на колонке, заполненной с окисью алюминия (нейтральная, III-IV ст. акт., $h=40,0 ; d=3,0$ см). Объем каждой фракции 100 мл. Элюирование проводили гексаном, смесью гексана и бензола $(2: 1 ; 1: 1)$, бензолом, смесью бензола и хлороформа $(3: 1 ; 2: 1)$, хлороформом и смесью хлороформа с этанолом $(95: 5)$.

\section{Обсуждение результатов}

Вещество, полученное из маточного раствора 17-й фракции, элюируемой бензолом (после выделения небольшого количества оксипеуцеданина), имеет состав $\mathrm{C}_{15} \mathrm{H}_{14} \mathrm{O}_{4}$, т. пл. $109-110^{\circ} \mathrm{C}$ (I) В ИК-спектре вещества I найдены полосы поглощения $\delta$-лактонного цикла $\left(1726 \mathrm{~cm}^{-1}\right)$ и двойных связей ароматической системы $\left(1648,1582,1458 \mathrm{~cm}^{-1}\right)$.

В ${ }^{1} \mathrm{H}$ ЯМР-спектре (рис. 1) исследуемого соединения в области метильных групп найдены сигналы двух метильных групп при 1,25 м.д. (d. J = 7,00 Hz, 6H) и однопротонный мультиплет при 3,20 м.д., свидетельствующие о присутствии в молекуле изопропильной $\left(\mathrm{CH}_{3}\right)_{2}-\mathrm{CH}-$ группы. Синглет с площадью $3 \mathrm{H}$ при 3,90 м.д. принадлежит метоксильной группе. В слабом поле спектра проявляются однопротонные сигналы при 6,40 (d., J = 9,65 Hz), 8,10 (d., J = 9,65 Hz), 7,60 (s) и 7,95 м.д. (s) соответственно, вызванные Н-4, Н-3, H-8, Н-5 ароматической системы.

Таким образом, на основании результатов, полученных при расшифровке ЯМР-спектра исследуемого соединения, ему предложено строение, идентичное строению пеуцеданина. Смешанная проба исследуемого вещества с достоверным образцом пеуцеданина депрессии температуры плавления не дает. ИК-спектры сравниваемых соединений идентичны. Вещество, выделенное из 34-36-й фракций после перекристаллизации из смеси гексана с хлороформом имеет состав $\mathrm{C}_{16} \mathrm{H}_{16} \mathrm{O}_{6}$ (II) и т. пл. $114-115^{\circ} \mathrm{C}$.

В ИК-спектре соединения II найдены полосы, гидроксильных групп (3400 $\left.\mathrm{cm}^{-1}\right)$, карбонильной группы $\delta$-лактонного цикла $\left(1700 \mathrm{~cm}^{-1}\right)$ и ароматической системы $\left(1627 ; 1592 \mathrm{~cm}^{-1}\right)$.
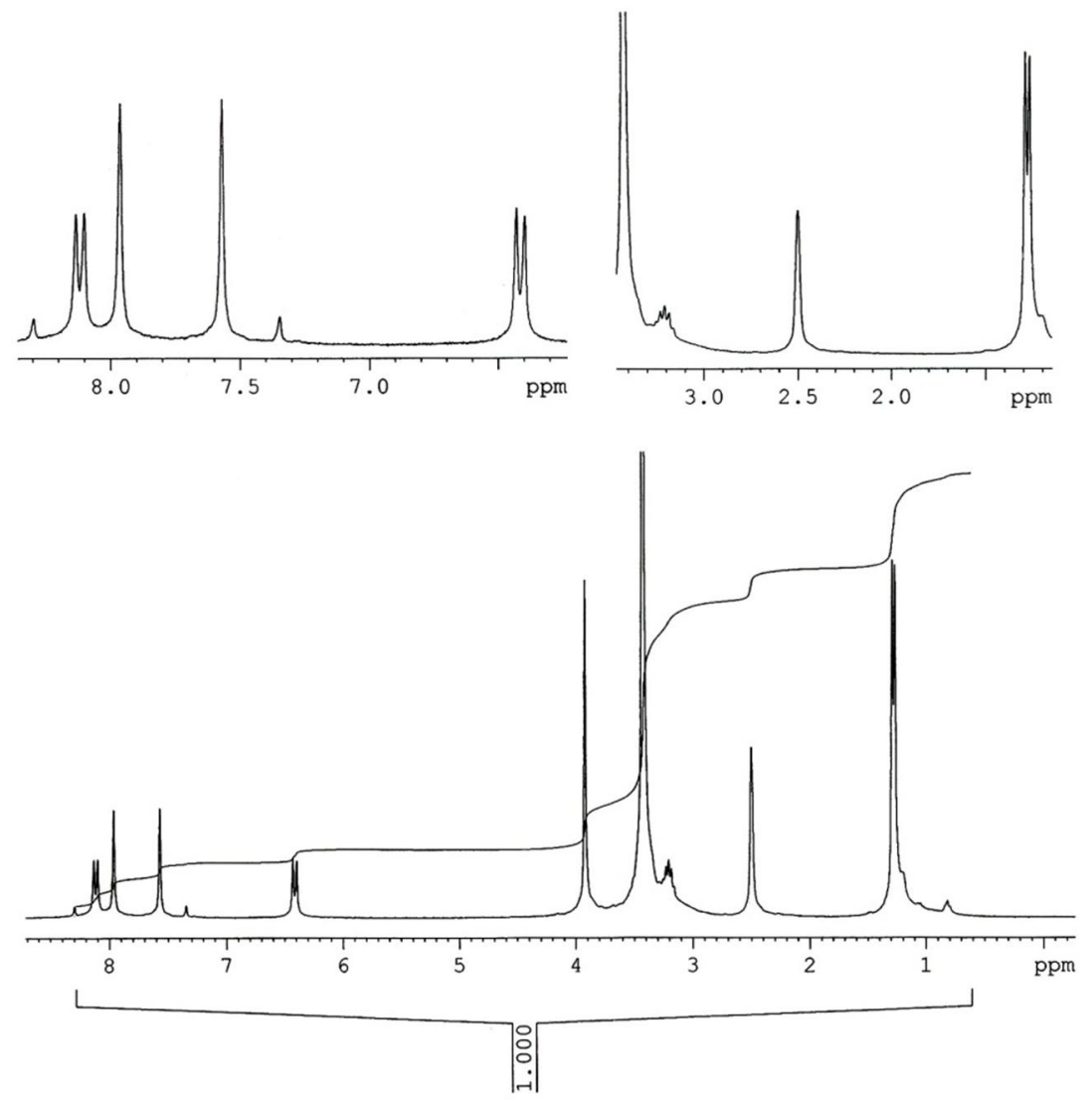

Рис. 1. ЯМР-спектр вещества I 
В ${ }^{13} \mathrm{C}$ ЯМР-спектре, снятом с полным подавлением спин-спинового взаимодействия с протонами, проявляются 16 синглетных сигналов, указывающих на присутствие в молекуле 16 атомов углерода. Из них два сигнала $(25,0$ и 28,0 м.д.) принадлежат метильным группам боковой цепи, один $(75,5$ м.д.) - метиновому и один (77,0 м.д.) - метиленовому атому углерода. Сигналы 94,0; 107,0; 112,0; 140,0; 147,0 м.д., обнаруживаемые как ${ }^{13} \mathrm{C}$, а также Dept 135 спектрами, относятся к протонированным $(-\mathrm{CH}=)$ углеродам ароматической системы. Сигналы, имеющиеся в ${ }^{13} \mathrm{C}-$-пектре и не найденные в ${ }^{13} \mathrm{C}$ Dept 135 спектре $(71,0 ; 108,0 ; 113,0 ; 150,0$; 152,$0 ; 158,0 ; 160,0$ м.д.), отнесены к непротонированным атомам углерода. Данные Dept 90 спектра подтверждают наличие в молекуле исследуемого вещества одной метинной (77,0 м.д., -CH-) и пяти ароматических $-\mathrm{CH}=$ групп (94,0;107,0; 113,0; 140,0; 147,0 м.д.). В ЯМР ${ }^{1} \mathrm{H}$ спектре (рис. 2) соединения обнаруживаются сигналы при 6,30 (d., J = 9,65 Hz, Н-3), 8,40 (d., J = 9,65 Hz, H-4), 7,20 (2H, Н-5 и Н-3'), 7,90 м.д. (1Н, Н-2'), которые позволяют приписать веществу II строения 8- (или 5-) замещенного линейного фурокумарина.

Два трехпротоных синглета при $1,10\left(\mathrm{CH}_{3}-\right)$ и 1,20 м.д. $\left(\mathrm{CH}_{3}-\right)$, однопротонные дублеты 4,70 (J = 4,65 Гц) и 5,20 м.д. (J = 5,06 Гц) и триплет при 4,25 м.д. $(\mathrm{J}=9,65$ Гц) наряду с сигналами при 3,70 (уширенный, t., J = 5,06 Гц, $1 \mathrm{H}, \mathrm{OH})$ и 4,25 м.д. (s., $1 \mathrm{H}, \mathrm{OH}$ у указывают на присутствие в молекуле боковой цепи (R).

$$
\mathrm{R}=-\mathrm{O}-\mathrm{CH}_{2} \underset{\mathrm{OH}}{\mathrm{CH}}-\mathrm{OH}_{3}^{-\mathrm{CH}_{3}}
$$

ИК- и ЯМР-спектры гидрата оксипеуцеданина не совпадают с таковыми исследуемого вещества (II). Следовательно, исследуемому веществу II соответствует строение, идентичное гидрату прангенина (II).<smiles>CC(C)(O)C(O)COc1c2occc2cc2ccc(=O)oc12</smiles>
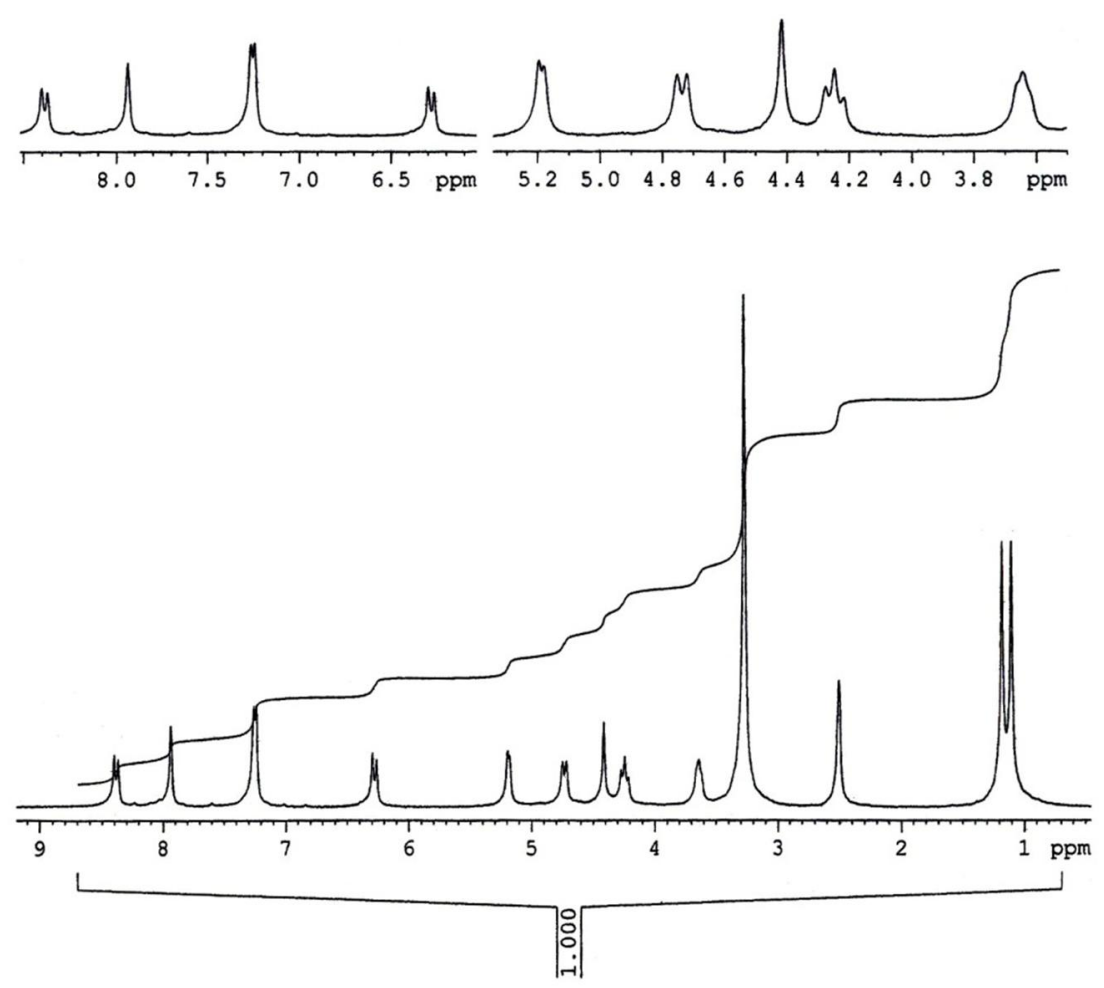

Рис. 2. ЯМР-спектр вещества II 


\section{Выводы}

Из корней Bilacunaria microcarpa (M. Bieb.) Pimenov \& V.N. Tikhom.выделены кумаринпроизводные состава $\mathrm{C}_{15} \mathrm{H}_{14} \mathrm{O}_{4}$, т. пл. $109-110{ }^{\circ} \mathrm{C}$ и $\mathrm{C}_{16} \mathrm{H}_{16} \mathrm{O}_{6}$; т. пл. $128-129{ }^{\circ} \mathrm{C}$.

На основании результатов, полученных при расшифровке ${ }^{1} \mathrm{H},{ }^{13} \mathrm{C},{ }^{13} \mathrm{C}$ Dept 135 , Dept 90 ЯMPспектров, доказано, что вещество I имеет структуру, идентичную пеуцеданину; вещество II - структуру, идентичную гидрату прангенина.

\section{Сиисок литературы}

1. Кузнецова Г.А. Природные кумарины и фурокумарины. Л., 1969. 248 с.

2. Керимов С.Ш. Исследование кумаринов и фурокумаринов из Hippomaratrum microcarpum (Bieb.) B. Fedtsch. и H. caspicum (DC.) Grossh.: автореф. дис. ... канд. хим. наук. Л., 1968. 11 с.

Поступило в редакичию 9 ноября 2013 г.

После переработки 24 мая 2014 г.

Mikailova N.Kh., Serkerov S.V. NEW COMPONENTS OF ROOT TAR OF THE BILACUNARIA MICROCARPA (M. BIEB.) PIMENOV \& V.N. TIKHOM.

Institute of Botany, National Academy of Sciences of Azerbaijan, Badamdar highway, 40, Baku, AZ1073 (Azerbaijan), e-mail: s.serkerov@mail.ru

The biologically active substances isolated from root resin of the Bilacunaria microcarpum M.Pimen. et V.Tichomirov. was investigated. Besides osthol, bergapten, izoimperatorin, oxypeucedanin, peucedanin hydrate, have been isolated two new individual crystalline compounds $\mathrm{C}_{15} \mathrm{H}_{14} \mathrm{O}_{4}$, m.p. $108-109{ }^{\circ} \mathrm{C}$ (I) and $\mathrm{C}_{16} \mathrm{H}_{16} \mathrm{O}_{6}$, m.p. $127-129{ }^{\circ} \mathrm{C}$ (II). On the basis of spectral the data (IR, ${ }^{1} \mathrm{H}$ NMR, ${ }^{13} \mathrm{C},{ }^{13} \mathrm{C}$ Dept 90, Dept 235) it was ascertained that they have a structure identical to the structure of peucedanin (I) and prangenin hydrate (II), respectively.

Keywords: Bilacunaria; coumarins; furocoumarins; prangenin hydrate; IR-; NMR-spectroscopy.

\section{References}

1. Kuznecova G.A. Prirodnye kumariny i furokumariny. [Natural coumarins and furokumariny]. Leningrad, 1969, 248 p. (in Russ.)

2. Kerimov S.Sh. Issledovanie kumarinov i furokumarinov iz Hippomaratrum microcarpum (Bieb.) B.Fedtsch. i H. caspicum (DC.) Grossh.: avtoref. dis. ... kand. him. nauk. [The study of coumarin and furokumarinov Hippomaratrum microcarpum (Bieb.) B.Fedtsch. and H. caspicum (DC.) Grossh.: the candidate of chemical sciences thesis]. Leningrad, 1968, $11 \mathrm{p}$.

Received November 9, 2013

Revised May 24, 2014

\footnotetext{
* Corresponding author.
} 